Научная статья

05.18.01 - Технология обработки, хранения и переработки злаковых, бобовых культур, крупяных продуктов, плодоовощной продукции и виноградарства (технические науки)

УДК 663.051

doi: 10.25712/ASTU.2072-8921.2021.03.007

\title{
ИСПОЛЬЗОВАНИЕ ПОЛУФАБРИКАТА ИЗ ARMILLARIA BOREALIS В ХЛЕБОПЕЧЕНИИ
}

\section{Жанна Александровна Кох ${ }^{1}$, Денис Александрович Кох ${ }^{2}$, Юлия Александровна Литовка ${ }^{3}$, Игорь Николаевич Павлов ${ }^{4}$}

\author{
1, 3, 4 Институт леса им. В.Н. Сукачева СО РАН, ФИЦ КНЦ, Красноярск, Россия \\ 1 jannetta-83@mail.ru, https://orcid.org/0000-0003-4016-7596 \\ 3 litovkajul@rambler.ru, https://orcid.org/0000-0001-5343-7896 \\ 4 forester24@mail.ru, https://orcid.org/0000-0001-7312-0933 \\ 1, 2 Красноярский государственный аграрный университет, Красноярск, Россия \\ 1 jannetta-83@mail.ru, https://orcid.org/0000-0003-4016-7596 \\ 2 dekoch@mail.ru, https://orcid.org/0000-0002-3047-1386 \\ 3,4 Сибирский государственный университет науки и технологий имени академика М.Ф. Решет- \\ нева, Красноярск, Россия \\ 3 litovkajul@rambler.ru, https://orcid.org/0000-0001-5343-7896 \\ 4 forester24@mail.ru, https://orcid.org/0000-0001-7312-0933
}

\begin{abstract}
Аннотация. Во всем мире пшеница является ведущим источником растительного белка в пище человека, поскольку в ней содержится больше белка, чем в кукурузе или рисе, других основных зерновых культурах. Базидиомицеты представляют собой наиболее развитый класс грибов, они способны синтезировать фрармакологически релевантные вторичные метаболиты, натуральные ароматизаторы и востребованные фрерменты. Благодаря своему биохимическому потенциалу, базидиомицеты являются идеальным инструментом для пищевой промышленности. Добавление грибного экстракта Armillaria borealis - это экономичный способ увеличить содержание биологически активных веществ в пшеничном хлебе. Вкус и аромат грибов Armillaria borealis также могут улучшить вкусовые качества хлеба. Целью данного исследования являлась возможность использования экстракта из мицелия Armillaria borealis в виде концентрата для повышения пищевой ценности пшеничного хлеба 1 сорта. Результаты, полученные экспериментальным путем, показали, что содержание легкогидролизуемых сахаров, в частности редуцирующих веществ, витаминов в концентрированном экстракте мицелия Armillaria borealis было выше, чем в экстракте мицелия Armillaria borealis, что является следствием концентрирования биохимических компонентов экстракта при определенном технологическом режиме концентрирования экстракта, биологически подкисленный хлеб характеризовался повышенным качеством, включая вкус, текстуру и срок годности. Добавление концентрата Armillaria borealis в рецептуру хлеба увеличивало водопоглощающую способность и время брожения теста, которое было связано со значительным снижением стабильности теста. Обогащение пшеничного хлеба 1 сорта концентратом Armillaria borealis вызвало значительные изменения в кислотности и влажности хлеба. Биологически подкисленный хлеб характеризовался повышенным качеством, включая вкус.

Ключевые слова: хлебопечение, обогащение, базидиомицеты, Armillaria borealis, концентрат, хлеб пшеничный 1 сорта, кислотность теста, брожение, биологически подкисленный хлеб.
\end{abstract}

Для цитирования: Использование полуфрабриката из Armillaria borealis в хлебопечении / Ж. А. Кох [и др.]. // Ползуновский вестник. 2021. № 3. С. 54-60 .doi: 10.25712/ ASTU.2072-8921.2021.03.007.

() Кох, Ж. А., Кох, Д. А., Литовка, Ю. А., Павлов, И. Н., 2021 
Original article

\title{
USE OF SEMI-FINISHED ARMILLARIA BOREALIS IN BAKERY
}

\author{
Zhanna A. Koch ${ }^{1}$, Denis A. Koch ${ }^{2}$, Yulia A. Litovka ${ }^{3}$, Igor N. Pavlov ${ }^{4}$ \\ 1, 3, 4 Sukachev Institute of Forest SB RAS, Federal Research Center «Krasnoyarsk Science Center SB \\ RAS», Krasnoyarsk, Russia \\ 1 jannetta-83@mail.ru, https://orcid.org/0000-0003-4016-7596 \\ 3 litovkajul@rambler.ru, https://orcid.org/0000-0001-5343-7896 \\ ${ }^{4}$ forester24@mail.ru, https://orcid.org/0000-0001-7312-0933 \\ 1,2 Krasnoyarsk State Agrarian University, Krasnoyarsk, Russia \\ 1 jannetta-83@mail.ru, https://orcid.org/0000-0003-4016-7596 \\ 2 dekoch@mail.ru, https://orcid.org/0000-0002-3047-1386 \\ ${ }^{3,4}$ Reshetnev Siberian State University of Science and Technology, Krasnoyarsk, Russia \\ 3 litovkajul@rambler.ru, https://orcid.org/0000-0001-5343-7896 \\ 4 forester24@mail.ru, https://orcid.org/0000-0001-7312-0933
}

\begin{abstract}
Wheat is the leading source of plant protein in human food around the world because it contains more protein than corn or rice, other staple grains. Basidiomycetes are the most advanced class of fungi. They are capable of synthesizing pharmacologically relevant secondary metabolites, natural flavors and sought-after enzymes. Because of their biochemical potential, Basidiomycetes are perfect tool for the food industry. Adding Armillaria borealis mushroom extract is an economical way to increase the bioactive content of wheat bread. The purpose of this study was to investigate the possibility of using an extract from the mycelium of Armillaria borealis in the form of a concentrate to increase the nutritional value of 1 st grade wheat bread. The results obtained experimentally showed that the content of easily hydrolyzable sugars, in particular reducing substances, vitamins in the concentrated extract of Armillaria borealis mycelium was higher than in the extract of Armillaria borealis mycelium which is a consequence of the concentration of the biochemical components of the extract at a certain technological mode of concentration of the extract, the biologically acidified bread was characterized by improved quality, including taste, texture and shelf life. The addition of Armillaria borealis concentrate to the bread formulation increased the water absorption capacity and fermentation time of the dough, which was associated with a significant decrease in the stability of the dough. Supplementation of 1st grade wheat bread with Armillaria borealis concentrate caused significant changes in the acidity and moisture content of the bread. The biologically acidified bread was characterized by improved quality, including flavor.
\end{abstract}

Keywords: baking, enrichment, basidiomycetes, Armillaria borealis, concentrate, wheat bread of the 1st grade, dough acidity, fermentation, biologically acidified bread.

Для цитирования: Koch, Zh. A., Koch, D. A., Litovka, Yu. A. \& Pavlov, I. N. (2021). Use of semifinished Armillaria Borealis in bakery. Polzunovskiy vestnik, (3), 54-60. (In Russ.). doi: 10.25712/ASTU.2072-8921.2021.03.007.

Обогащение пищевых продуктов определяется как добавление одного или нескольких питательных веществ к пище для улучшения ее качества для людей, потребляющих обычно с целью уменьшения или контроля дефицита питательных веществ. В хлебе классической рецептуры недостаточно белка для питания человека. Базидиомицеты представляют собой наиболее развитый класс грибов. Они способны синтези- ровать фрармакологически релевантные вторичные метаболиты, натуральные ароматизаторы и востребованные ферменты. Благодаря своему биохимическому потенциалу базидиомицеты являются идеальным инструментом для пищевой промышленности $[1,2]$.

Во всем мире пшеница является ведущим источником растительного белка в пище человека, поскольку в ней содержится больше белка, чем в кукурузе или рисе, дру- 
гих основных зерновых культурах. Хлеб - это основной продукт питания, который готовят путем приготовления теста из муки и воды, а часто и из дополнительных ингредиентов [3].

Грибы - это простые формы растительной жизни, богатый источник белков, витаминов и минералов. Низкое содержание в грибах углеводов и липидов делает их идеальной пищей для диабетиков и людей, которые хотят избавиться от лишнего веса [4-6].

Большинство съедобных разновидностей грибов принадлежит к семейству Agaricaceae класса базибиомицетов. Съедобные грибы занимают центральное место среди низших организмов. В развитых странах грибы стали одной из важнейших садовых культур. Производство грибов растет во всем мире. Грибы являются хорошим источником железа, меди, кальция, калия, витамина D, фолиевой кислоты, цинка и т. д. Специально отобранные штаммы сушеных грибов используются для производства грибных порошков и экстрактов. В настоящее время во всем мире используют грибы в качестве продуктов питания и лекарств. Принимая во внимание вышеизложенное, настоящее исследование было направлено на достижение следующих цели и задач. Добавление грибного экстракта Armillaria borealis - это экономичный способ увеличить содержание биологически активных веществ в пшеничном хлебе. Вкус и аромат грибов Armillaria borealis также могут улучшить вкусовые качества хлеба $[7,8]$.

Целью данного исследования являлась возможность использования экстракта из мицелия Armillaria borealis в виде концентрата для повышения пищевой ценности пшеничного хлеба 1 сорта.

Для достижения поставленной цели необходимо решить следующие задачи:

1. Изучить биохимический состав экстракта из Armillaria borealis и полученного концентрата из него.

2. Разработать рецептуру хлеба пшеничного из муки 1 сорта с добавлением концентрата.

3. Провести анализ влияния концентрата на органолептические и фризик-химические показатели хлеба пшеничного 1 сорта.

\section{МАТЕРИАЛЫ И МЕТОДЫ ИССЛЕДОВАНИЯ}

Сырьем для приготовления теста для хлеба была выбрана мука пшеничная 1 сорта, хлебопекарные прессованные дрожжи, соль, концентрат экстракта Armillaria borealis. Высушенный мицелий Armillaria borealis нарезали ножом на мелкие кусочки и экстрагиро56 вали с помощью экстрагента (водно-этанольной смесью) концентрацией $38 \%$ при $55^{\circ} \mathrm{C}$ в течение трех часов, содержащей $3 \%$ соли и 0,01 \% лимонной кислоты. Затем экстрагент сливали и концентрировали с отгонкой растворителя на роторном вакуум-выпарном испарителе при температуре $40{ }^{\circ} \mathrm{C}$ и давлении 0,06 МПа в течение 3 часов. После охлаждения до комнатной температуры концентрат экстракта Armillaria borealis разливали в емкости из темного стекла и плотно закрывали крышками для дальнейшего использования в качестве полуфабриката при производстве хлеба пшеничного 1 сорта. Биохимический анализ концентрата экстракта Armillaria borealis проводили по методикам, принятым в биохимии растений [3]. Общее содержание белка в концентрате определяли по методу Бузуна. Определение витаминов - по методикам Девяткина; суммарного количества углеводов - по методике Вознесенского. Количество зольных веществ определяли спектрофотометрическим методом; содержание и состав липидов - по методикам Кейтс [9, 10]. Пшеничное тесто готовили безопарным способом. В состав рецептуры хлеба пшеничного 1 сорта входило следующее сырье: пшеничная мука 1 сорта (100\%), вода, соль (1,5\% муки) и прессованные дрожжи (3\%). Образцы хлеба были приготовлены с использованием 5, 10, 15 и $20 \%$ концентрата экстракта Armillaria borealis от массы муки. После выпечки оценивали органолептические и физико-химические показатели хлеба.

\section{РЕЗУЛЬТАТЫ ИССЛЕДОВАНИЯ И ИХ ОБСУЖДЕНИЕ}

Биохимический состав полученного концентрата из экстракта мицелия Armillaria borealis приведен в таблице 1.

Таблица 1 - Биохимический состав концентрата и экстракта мицелия Armillaria borealis

Table 1 - Biochemical composition of concentrate and extract of Armillaria borealis mycelium

\begin{tabular}{|c|c|c|}
\hline \multirow{2}{*}{ Показатель } & \multicolumn{2}{|c|}{$\begin{array}{c}\text { Содержание г/100 г } \\
\text { сырой массы }\end{array}$} \\
\cline { 2 - 3 } & Концентрат & Экстракт \\
\hline 1 & 2 & 3 \\
\hline Белок, \% & $9,25 \pm 0,03$ & $7,75 \pm 0,05$ \\
\hline $\begin{array}{c}\text { Фенольные } \\
\text { соединения, \% }\end{array}$ & $5,17 \pm 0,04$ & $4,11 \pm 0,02$ \\
\hline Липиды, \% & $4,05 \pm 0,04$ & $3,27 \pm 0,02$ \\
\hline $\begin{array}{c}\text { Суммарное количе- } \\
\text { ство углеводов, \% }\end{array}$ & $89,58 \pm 0,03$ & $63,27 \pm 0,08$ \\
\hline
\end{tabular}

ПОЛЗУНОВСКИЙ ВЕСТНИК № 32021 
Продолжение таблицы 1 / Table 1 cont.

\begin{tabular}{|c|c|c|}
\hline \multicolumn{3}{|c|}{ Витамины: } \\
\hline 1 & 2 & 3 \\
\hline $\begin{array}{c}\text { Аскорбиновая } \\
\text { кислота } \\
\text { (витамин С), мг }\end{array}$ & $65,33 \pm 0,07$ & $38,12 \pm 0,04$ \\
\hline $\begin{array}{c}\text { Тиамин } \\
\text { (витамин В1), мг }\end{array}$ & $2,65 \pm 0,05$ & $0,45 \pm 0,02$ \\
\hline $\begin{array}{c}\text { Рибофлавин } \\
\text { (витамин В2), мг }\end{array}$ & $1,68 \pm 0,08$ & $0,52 \pm 0,04$ \\
\hline $\begin{array}{c}\text { Ниацин } \\
\text { (витамин В3), мг }\end{array}$ & $8,85 \pm 0,04$ & $4,52 \pm 0,04$ \\
\hline $\begin{array}{c}\text { Пиридоксин } \\
\text { (витамин В6), мг }\end{array}$ & $1,73 \pm 0,09$ & $0,58 \pm 0,03$ \\
\hline $\begin{array}{c}\text { Фолиевая кислота } \\
\text { (витамин В9), мг }\end{array}$ & $22,87 \pm 0,07$ & $15,24 \pm 0,05$ \\
\hline $\begin{array}{c}\text { Каротиноды } \\
\text { (в пересчете на } \beta-\end{array}$ & $114,21 \pm 0,03$ & $87,35 \pm 0,04$ \\
\hline каротин), мкг & $3,84 \pm 0,06$ & $3,15 \pm 0,03$ \\
\hline $\begin{array}{c}\text { Токофрерол } \\
\text { (витамин Е), мг }\end{array}$ & 3,04 \\
\hline
\end{tabular}

Содержание белка было самым высоким в концентрате экстракта мицелий Armillaria borealis и его количество отличалось в 1,5 раза. Из таблицы 1 содержание легкогидролизуемых сахаров, в частности редуцирующих веществ, витаминов в концентрированном экстракте мицелия Armillaria borealis, было выше, чем в экстракте мицелия Armillaria borealis, что является следствием концентрирования биохимических компонентов экстракта при определенном технологическом режиме. В связи с вышеизложенным, разработка научно обоснованной технологии приготовления хлеба с использованием концентрата экстракта мицелия Armillaria borealis является актуальным и имеет важное теоретическое и практическое значение.

Добавление концентрата экстракта мицелия Armillaria borealis в рецептуру хлеба в количестве от 5 до $20 \%$ от массы муки увеличивало кислотность в зависимости от времени брожения теста. Повышение кислотности теста было отмечено в интервале брожения с 90 до 120 минут для всех образцов теста, но значительное повышение кислотности было характерно для образцов с 15 и $20 \%$ концентрата экстракта мицелия Armillaria borealis от массы муки (рисунок 1). Химический состав хлеба с добавлением концентрата Armillaria borealis представлен в таблице 2 .

Анализ, приведенный в таблице 2, показывает, что содержание белка в $5 \%$ хлебе с концентратом Armillaria borealis от массы муки составляет 10,07\%. Кроме того, в результате было обнаружено, что хлеб с $10 \%$ конPOLZUNOVSKIY VESTNIK № 32021 центрата Armillaria borealis от массы муки содержит 10,74 \%.

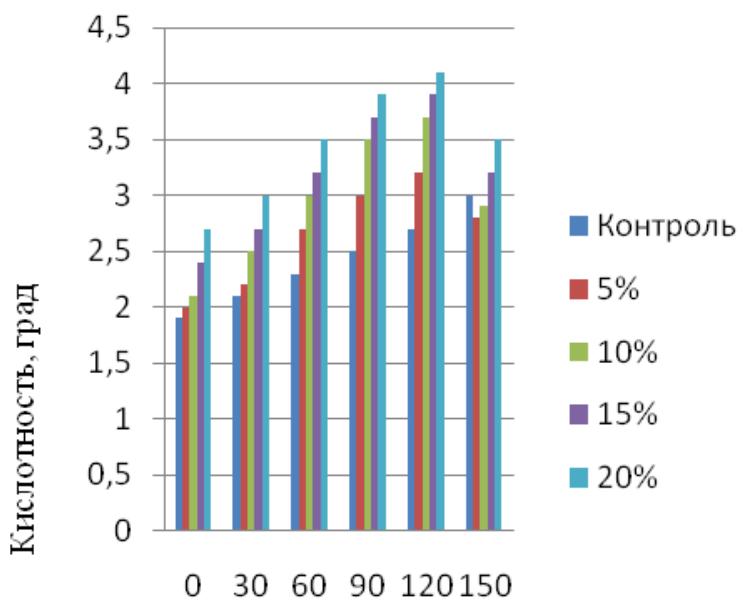

Время броження, мннут

Рисунок 1 - Влияние концентрата экстракта мицелия Armillaria borealis на кислотность теста в процессе брожения

Figure 1 - Influence of Armillaria borealis mycelium extract concentrate on dough acidity during fermentation

Таблица 2 - Химический состав хлеба с добавлением концентрата Armillaria borealis

Table 2 - Chemical composition of bread with the addition of Armillaria borealis concentrate

\begin{tabular}{|c|c|c|c|c|c|}
\hline 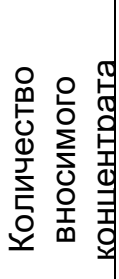 & 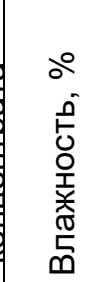 & $\begin{array}{l}\text { o̊ } \\
\text { ò } \\
\text { ○े } \\
\text { ம் }\end{array}$ & $\begin{array}{l}\stackrel{0}{0} \\
\frac{\tilde{0}}{5} \\
\frac{5}{5} \\
\frac{5}{5}\end{array}$ & 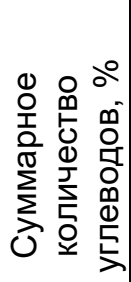 & 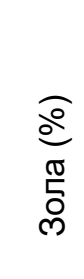 \\
\hline $\begin{array}{l}\text { Кон- } \\
\text { троль }\end{array}$ & 15,05 & 7,9 & 1,5 & 48,3 & 1,45 \\
\hline $5 \%$ & 16,04 & 10,07 & 9.20 & 72,87 & 1,82 \\
\hline $10 \%$ & 17,31 & 10,74 & 9,73 & 68,16 & 2,01 \\
\hline $15 \%$ & 17,54 & 11,40 & 10,10 & 68,76 & 2,20 \\
\hline $20 \%$ & 19,36 & 11,45 & 10,15 & 68,54 & 2,23 \\
\hline
\end{tabular}

Содержание белка в грибном хлебе увеличилось с 0,47\% до 1,8 \% в хлебе с $5 \%$ и $15 \%$ концентрата Armillaria borealis от массы муки соответственно. Это увеличение содержания белка связано с добавлением в хлеб разного количества концентрата Armillaria borealis. Белок в пшенице и белок в грибах 
ответственны за это повышение содержания белка в грибном хлебе.

Дегустационная оценка образцов хлеба пшеничного 1 сорта с добавлением концен- трата экстракта мицелия Armillaria borealis (рисунок 2) проводилась по тридцатибалльной системе.

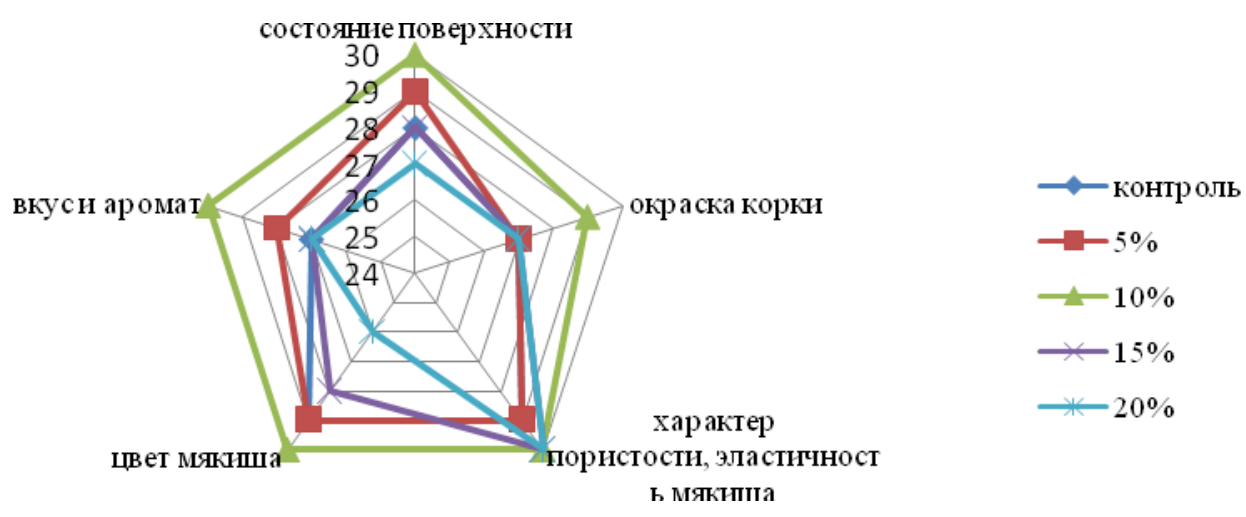

Рисунок 2 - Профильная диаграмма дегустационной оценки хлеба пшеничного 1 сорта с добавлением концентрата экстракта мицелия Armillaria borealis

Figure 2 - Profile diagram of the tasting assessment of wheat bread of the 1st grade with the addition of the extract concentrate of Armillaria borealis mycelium

В результате проведенной дегустационной оценки был сделан вывод об улучшении органолептических характеристик хлеба пшеничного 1 сорта с добавлением $10 \%$ концентрата экстракта мицелия Armillaria borealis от массы муки.

Физико-химические показатели образцов хлеба из пшеничной муки 1 сорта обогащенных концентратом экстракта мицелия Armillaria borealis (таблица 3) определялись в соответствии с ГОСТ Р 58233-2018 [4].

Качественные характеристики хлеба, как было обнаружено, значительно улучшаются, когда добавляется 10 \% концентрата экстракта мицелия Armillaria borealis от массы муки.

Выход хлеба зависит от количества воды, поглощенной мукой в процессе выпечки. Выход хлеба в проведенных исследованиях значительно увеличился при внесении концентрата Armillaria borealis в количестве $15 \%$ и $20 \%$ от массы муки.

Значительно меньший объем хлеба наблюдался при концентрации $5 \%$, тогда как более высокая пористость была характерна для хлеба, обогащенного 20 \% долей концентрата Armillaria borealis от массы муки.

Обогащение пшеничного хлеба с помощью концентрата Armillaria borealis вызвало значительные изменения кислотности и влажности хлеба. Содержание влаги можно объяснить более высокой водопоглощающей способностью теста. Кислотность хлеба может быть увеличена путем внесения определенного количества концентрата Armillaria borealis.
Таблица 3 - Физико-химические показатели образцов хлеба из пшеничной муки 1 сорта, обогащенных концентратом экстракта мицелия Armillaria borealis

Table 3 - Physicochemical parameters of bread samples from 1st grade wheat flour, enriched with the extract concentrate of Armillaria borealis mycelium

\begin{tabular}{|c|c|c|c|}
\hline 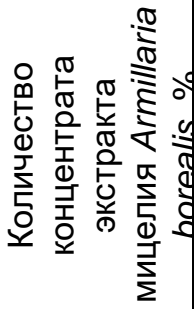 & 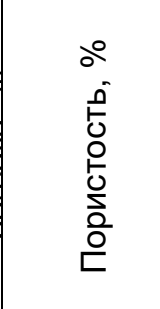 & 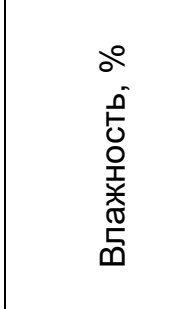 & 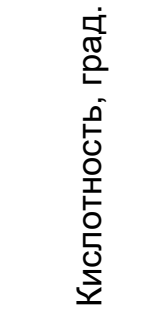 \\
\hline Контроль & $69 \pm 0,07$ & $43,2 \pm 0,03$ & $3,0 \pm 0,05$ \\
\hline 5 & $70 \pm 0,08$ & $43,9 \pm 0,02$ & $2,8 \pm 0,03$ \\
\hline 10 & $71 \pm 0,09$ & $44,2 \pm 0,04$ & $2,9 \pm 0,06$ \\
\hline 15 & $72 \pm 0,06$ & $45,6 \pm 0,07$ & $3,2 \pm 0,07$ \\
\hline 20 & $74 \pm 0,04$ & $47,1 \pm 0,05$ & $3,5 \pm 0,08$ \\
\hline
\end{tabular}

\section{ЗАКЛЮЧЕНИЕ}

Результаты показали, что биологически подкисленный хлеб характеризовался повышенным качеством, включая вкус, текстуру и срок годности. Добавление концентрата Armillaria borealis в рецептуру хлеба увеличивало водопоглощающую способность и время брожения теста, которое было связано со ПОЛЗУНОВСКИЙ ВЕСТНИК № 32021 
значительным снижением стабильности теста. Обогащение хлеба пшеничной муки 1 сорта концентратом Armillaria borealis вызвало значительные изменения в кислотности и влажности хлеба. Биологически подкисленный хлеб характеризовался повышенным качеством, включая вкус. Результаты настоящего исследования могут помочь в разработке коммерческой технологии переработки для эфрфективного использования концентрата экстракта мицелия Armillaria borealis, особенно для производства хлеба.

\section{СПИСОК ЛИТЕРАТУРЫ}

1. Baumgartner K., Coetzee M.P., Hoffmeister, D. Secrets of the subterranean pathosystem of Armillaria. Mol Plant Pathol. 2011. 12 (6). 515-34.

2. Борисенко М.В., Кох Д.А. Использование полуфабриката из мелкоплодных яблок в производстве ржано-пшеничного хлеба // Инновационные тенденции развития российской науки. 2016. C. 3-5.

3. Еремеева Н.Б., Макарова Н.В. Изучение влияния предварительной обработки плодов и ягод ферментными препаратами на выход и антиоксидантную активность экстрактов // Вестник КамчатГТУ. 2018. № 43. С. 55-59.

4. Бухало А.С. Высшие съедобные базидиомицеты в чистой культуре. Киев, 1988. 144 с.

5. Павлов И.Н., Литовка Ю.А., Литвинова Е.А., Тимофеев А.А., Пашенова Н.В., Сафронова И.Е., Кулаков С.С., Мулява В.В., Мулява В.E. Armillaria borealis Marxm. \& Korhonen: распространение, фитопатогенность и морфологокультуральные особенности // АгроЭкоИнфо. 2017. № 3 (29). С. 18.

6. Литвинова Е.А., Антипова Т.В., Баскунов Б.П., Желифонова В.П., Козловский А.Г., Литовка Ю.А., Павлов И.Н. Сибирские штаммы грибов рода armillaria - продуценты перспективных лекарственных препаратов из группы // Успехи медицинской микологии. 2018. Т. 19. С. 158-160.

7. Крячко Т.И., Малкина В.Д., Мартиросян В.В. Разработка стандартов организации для обеспечения качества и безопасности порошков из интродукционного растительного сырья обогащенного селеном // Инновационные исследования и разработки для научного обеспечения производства и хранения экологически безопасной сельскохозяйственной и пищевой продукции. Краснодар. 2019. C. $374-381$.

8. Хамельман Дж. Хлеб. Технология и рецептуры. Пер. с англ. 2-е изд., перераб. и доп. СПб. : Профессия. 2017. 544 с.

9. Ушанова В.М., Лебедева, О.И., Девятловская, А.Н. Основы научных исследований. Красноярск, 2004. Ч. 3. 359 с.

10. Позняковский В.М. Гигиенические основы питания, безопасность и экспертиза продовольственных товаров. Новосибирск : Изд-во Новосибирского университета, 1999. 447 с.

\section{Информация об авторах}

Ж. А. Кох - научный сотрудник лаборатории лесных культур, микологии и фотопатологии Института леса им. В.Н. Сукачева СО РАН, ФИЦ КНЦ, доцент кафедры технологии, оборудования бродильных и пищевых производств «Красноярский государственный аграрный университет».

Д. А. Кох - к.т.н., доцент кафредры технологии хлебопекарного, кондитерских и макаронных производств «Красноярский государственный аграрный университет».

Ю. А. Литовка - старший научный сотрудник лаборатории лесных культур, микологии и фитопатологии Института леса им. В.Н. Сукачева СО РАН, ФИЦ КНЦ, д.б.н., профрессор кафеедры химической технологии древесины и биотехнологии "Сибирский государственный университет науки и технологий имени академика М.Ф. Решетнева».

И. Н. Павлов - заведующий лабораторией лесных культур, микологии и фитопатологии, Института леса им. В. Н. Сукачева СО РАН, ФИЦ КНЦ, Ә.б.н., профрессор, заведующий кафредры химической технологии древесины и биотехнологии "Сибирский государственный университет науки $и$ технологий имени академика М.Ф. Решетнева».

\section{REFERENCES}

1. Baumgartner, K., Coetzee, M.P. \& Hoffmeister, D. (2011). Secrets of the subterranean pathosystem of Armillaria. Mol Plant Pathol. 12 (6). 515-34.

2. Borisenko, M.V. \& Koh, D.A. (2016). The use of semi-finished products from small-fruited apples in the production of rye-wheat bread. Innovative trends in the development of Russian science. 3-5. (In Russ).

3. Eremeeva, N.B. \& Makarova, N.V. (2018). Study of the effect of pretreatment of fruits and berries with enzyme preparations on the yield and antioxidant activity of extracts. Bulletin of Kamchatka State Technical University. (43), 55-59. (In Russ).

4. Bukhalo, A.S. (1988). Higher edible Basidiomycetes in pure culture. Kiev. (In Russ).

5. Pavlov, I.N., Litovka, Yu.A., Litvinova, E.A., Timofeev, A.A., Pashenova, N.V., Safronova, I.E., Kulakov, S.S., Mulyava, V.V. \& Mulyava V.E. (2017). Armillaria borealis Marxm. \& Korhonen: distribution, phytopathogenicity and morphological and cultural features. Agro-Ecolnfo. 3 (29), 18. (In Russ).

$$
\text { 6. Litvinova, E.A., Antipova, }
$$

T.V., Baskunov, B.P., Zhelifonova, V.P., Kozlovsky, A.G., Litovka, Yu.A. \& Pavlov, I.N. (2018). Siberian strains of fungi of the genus armillaria, producers of promising drugs from the group. Advances in medical mycology. (19), 158-160. (In Russ). 
7. Kryachko, T.I., Malkina, V.D. \& Martirosyan, V.V. (2019). Development of organizational standards to ensure the quality and safety of powders from introductory plant raw materials enriched with selenium. Innovative research and development for scientific support of production and storage of environmentally friendly agricultural and food products. Krasnodar. P. 374-381. (In Russ).

8. Bread, J. Hamelman. (2017). Technology and recipes. Per. from English 2nd ed., Revised and enlarged. SPb . : Profession. (In Russ).

9. Ushanova, V.M., Lebedeva, O.I. \& Devyatlovskaya, A.N. (2004). Fundamentals of scientific research: Krasnoyarsk. 3-359. (In Russ).

10. Poznyakovsky, V.M. (1999). Hygienic Basics of Nutrition, Safety and Expertise of Food Products. Novosibirsk: Novosibirsk University Press (in Russ).

\section{Information about the authors}

Zh. A. Koch - researcher of the Laboratory of Forest Crops, Mycology and Phytopathology (Sukachev Institute of Forest SB RAS, Federal Research Center "Krasnoyarsk Science Center SB RAS»), Associate Professor of the Department of Technology, Equipment for Fermenta- tion and Food Production (Krasnoyarsk State Agrarian University).

D. A. Koch - Candidate of Technical Sciences, Associate Professor of the Department of Technology of Bakery, Confectionery and Macaroni Production (Krasnoyarsk State Agrarian University).

Yu. A. Litovka - senior researcher of the Laboratory of Forest Cultures, Mycology and Phytopathology (Sukachev Institute of Forest SB RAS, Federal Research Center "Krasnoyarsk Science Center SB RAS»), Doctor of Biological Sciences, Professor of the Department of Chemical Technology of Wood and Biotechnology (Reshetnev Siberian State University of Science and Technology).

I. N. Pavlov - head of the laboratory of forest cultures, mycology and phytopathology, (Sukachev Institute of Forest SB RAS, Federal Research Center «Krasnoyarsk Science Center SB RAS»), Doctor of Biological Sciences, Professor, Head of the Department of Chemical Technology of Wood and Biotechnology (Reshetnev Siberian State University of Science and Technology).

Авторы заявляют об отсутствии конфликта интересов.

The authors declare that there is no conflict of interest.

Статья поступила в редакцию 11.06.2021; одобрена после рецензирования 10.09.2021; принята к публикации 17.09.2021.

The article was received by the editorial board on 11 June 21; approved after editing on 10 Sep 21; accepted for publication on 17 Sep 21. 